\section{Petroleum Ether Separation and Seedcoat Removal Enhance Seed Germination of a Casuarina equisetifolia L. $\times$ C. glauca Sieb. ex Spreng Hybrid}

\author{
Xiuli Shen, William S. Castle ${ }^{1}$, and Frederick G. Gmitter, Jr. \\ Horticultural Sciences Department, University of Florida, IFAS, Citrus \\ Research and Education Center (CREC), 700 Experiment Station Road, \\ Lake Alfred, FL 33850
}

Additional index words. Casuarina cunninghamiana, flotation separation, plant propagation

Abstract. Casuarina cunninghamiana Miq. is an introduced species to Florida that has potential as a windbreak plant to help manage canker in citrus groves; however, only Florida sources can be used for that purpose. Local sources of Casuarina are generally adequate seed producers, but germination percentages are frequently poor. Thus, the causes of low seed germination and methods to improve germination were investigated using $C$. cunninghamiana and a local hybrid $(C$. equisetifolia $\mathrm{L} . \times C$. glauca Sieb. ex Spreng.). Seeds of the hybrid were larger and heavier $(88 \mathrm{mg} / 100 \mathrm{seeds})$ than those of $C$. cunninghamiana (mean wt. $67 \mathrm{mg} / 100$ seeds). Shrunken, insect-damaged, and empty seeds, present in all unsorted seed lots, were responsible for poor seed germination of the four seed sources studied. Petroleum ether separation improved germination by dividing seeds into floaters and sinkers. The floater fraction consisted of $47.5 \%$ to $93 \%$ insectdamaged seeds compared with $\mathbf{9 . 0} \%$ to $\mathbf{4 3 . 5 \%}$ among sinkers. More than $\mathbf{5 0 \%}$ of the sinkers were filled seeds and less than $21 \%$ in floaters. No empty seeds were sinkers except for one source of $C$. cunninghamiana. In sorted hybrid seeds, petroleum ether separation eliminated a large proportion of ungerminable seeds (floaters) and seed germination among sinkers was faster with a higher germination percentage than floaters. Cumulative germination of hybrid seeds in a trial involving two temperatures was $23.0 \%$ for sunken seeds at $30{ }^{\circ} \mathrm{C}$ at the end of 8 weeks compared with $1 \%$ of unsorted seeds. Temperature had no significant effect on seed germination. The germination percentage of hybrid seeds with seedcoats removed was $91.0 \%$ in the first week of culture compared with only $1.2 \%$ in the first week and $12.6 \%$ seed germination at the end of 8 weeks' culture of intact seeds.

The genus Casuarina, also commonly known as Australian pine, she-oak, sheoak, ironwood, or beefwood, is a member of the family Casuarinaceae and is composed of 96 species native to Australia, southeastern Asia, and islands of the western Pacific Ocean (Castle et al., 2008; Turnbull, 1990; Wilson and Johnson, 1989). Casuarina spp. has been grown in tropical and subtropical regions as a multipurpose tree species, including uses as a windbreak to mitigate strong winds, for rehabilitation in stabilizing desert and coastal dunes, as ornamental trees, and for firewood, timber, and pulpwood production (Castle et al., 2008; Midgley et al., 1983; Samasundaram and Jagadees, 1977).

Three species of Casuarina, C. glauca, $C$. equisetifolia, and C. cunninghamiana, were introduced to Florida $\approx 100$ years ago (Castle et al., 2008). Since then, trees of those species have spread largely in southern Florida, but

Received for publication 17 Feb. 2009. Accepted for publication 25 Mar. 2009.

${ }^{1}$ To whom reprint requests should be addressed; e-mail bcastle@ufl.edu. the tree, and wind sturdiness. Those traits are especially valuable in established groves of the low elevation, poorly drained Florida coastal areas where space to add a windbreak is limited by drainage waterways, and the bedding required for planting citrus. C. cunninghamiana trees can be planted in single lines minimizing any need to remove citrus trees.

Casuarina can be propagated by vegetative means or with seed, but with highly variable and often inconsistent results (Goh et al., 1995; Lundquist and Torrey, 1984). It is commonly propagated for commercial forestry applications by seeds because they are easy to collect, handle, and store and are plentiful (El-Lakany et al., 1990). A single mature tree of Casuarina is capable of producing a large quantity of cones that each yield many seeds (El-Lakany et al., 1989; Turnbull and Martensz, 1982). However, the seeds of Casuarina spp. often germinate poorly (Jerlin and Srimathi, 1997). They frequently have germination percentages less than $50 \%$, slow germination rates, and exhibit considerable variability in their germination characteristics regardless of whether the seeds were from a species or an interspecific hybrid (El-Lakany et al., 1989; ElLakany and Shepherd, 1983; Goh et al., 1995; Turnbull and Martensz, 1983).

Germination is inconsistent apparently because of nonviable seeds that have no or underdeveloped embryos, have been insectdamaged, or are "shrunken" (Mahadevan et al., 1999; Sivakumar et al., 2007; Umarani and Vanangamudi, 2002). Methods for eliminating these unusable seeds could improve germination. Flotation is one widely used technique to separate filled seeds from ungerminable seeds by their difference in specific gravity (Barabin, 1983; Mani et al., 2002; McLemore, 1965; Simak, 1973). Also, the seed of Casuarina is botanically classified as a dry, indehiscent samara with a single wing and has a hard, thick seedcoat. The seedcoat can inhibit seed germination by virtue of mechanical restraint, acting as a barrier to gas or water exchange, or being a source of inhibitors (Martinez-Honduvilla and SantosRuiz, 1978; Toole et al., 1956). Removing the seedcoat to improve seed germination rate in Casuarina has not been reported.

Despite concern about invasiveness, the Florida legislature granted citrus growers limited permission to use C. cunninghami$a n a$, a dioecious species, as a windbreak with the caveat that it not be seed-propagated; only vegetatively propagated male plants were allowed and cuttings could only be taken from Florida sources of plant material (Castle, 2008). Nevertheless, seed propagation is the preferred method and may eventually be allowed if plants could be identified by gender before flowering.

We hypothesized that the seed germination of Florida Casuarina sources could be improved with proper treatment; thus, our objectives were to: 1) examine seed morphological characteristics among Casuarina spp. and causes of low seed germination; and 
2) determine the effectiveness of petroleum ether separation and seedcoat removal on seed germination.

\section{Materials and Methods}

\section{Seed sources}

Mature brown cones were collected on 5 Mar. $2008(\approx 11$ months after flowering) from a naturalized $C$. equisetifolia $\times C$. glauca $($ C. e. $\times$ C. g. $)$ tree of unknown age located $\approx 15 \mathrm{~km}$ west of Vero Beach, FL (lat. 27.70123, long. 80.50877) and growing along a ditch bank within a citrus grove. The hybrid nature of the plant was determined by amplified fragment length polymorphism analysis (J. Gaskin, USDA-ARS, personal communication). Mature brown cones were also collected on 27 Mar. 2008 from three unknown age trees of $C$. cunninghamiana $(C$. c.) located in Ruskin, FL (lat. 27.72834, long. 82.42944) numbered C. c.\#1, C. c.\#5, and C. c.\#14, respectively. Cones were allowed to dehisce at room temperature $\left(20{ }^{\circ} \mathrm{C}\right)$ for $2 \mathrm{~d}$ and then placed in plastic storage bags and shaken to ensure that all seeds were collected.

\section{Seed viability test}

Seeds were tested for viability using tetrazolium [2, 3, 5-triphenyltetrazolium chloride (TZ); Sigma-Aldrich, Castle Hill, Australia]. Fifty unsorted seeds were randomly selected from each of the four sources and the seedcoat carefully removed under a light microscope (Leica Zoom 2000, Model Z45L; Leica Inc., Buffalo, NY). Each seed was cut in half longitudinally through the embryo with a sharp scalpel. Half of each seed was placed in a petri dish $(100 \times 15$ $\mathrm{mm}^{2}$ ) on a single sheet of 9-cm filter paper and covered with a freshly made $1 \% \mathrm{TZ}$ solution. Petri dishes were placed in the dark for $4 \mathrm{~h}$ and any color change in the seed was noted. For the C. e. $\times$ C. g. hybrid seeds, the embryo as well as other tissues stained red indicating viability, although the embryo exhibited a deeper red color than the other seed tissues. For the $C$. c. seeds, no color change was observed showing none or low viability. Thus, seeds from the three $C$. $c$. trees were not used for the seed germination trials; they were only used for morphological examination.

\section{Morphological examination}

The weight of five samples of 100 unsorted seeds from each of the four sources was measured. Another sample of $\approx 250$ to 300 unsorted seeds of each source was placed on the surface of petroleum ether (specific density $=0.64$; boiling point 30 to $60{ }^{\circ} \mathrm{C}$; Fisher Scientific, Fair Lawn, NJ) in a 2000$\mathrm{mL}$ beaker with $\approx 1800 \mathrm{~mL}$ of petroleum ether and stirred mechanically for $2 \mathrm{~min}$ and then allowed to separate for another minute without stirring. Seeds designated as floaters or sinkers were collected, classified into four groups (filled, shrunken, insect-damaged, and empty) based on their morphological traits (Figs. 1 and 2) as observed by light microscopy, and counted. Filled seeds were soft with a fully developed embryo and a light creamy color; partially filled seeds had a flat end where the embryo would normally be located and were counted as shrunken; empty seeds were nonfilled seeds with only a seedcoat; seeds with a hole and having a dark color were regarded as insect-damaged.

\section{Preliminary experiments}

We observed that the seedcoat of Casuarina was hard, as reported, and difficult to remove. When seeds were soaked in water, they tended to clump and did not separate easily apparently because of sticky substances on the seed wing. In a preliminary study to determine if the seedcoat could be softened and seeds dewinged, samples were soaked for 15 min in: 1) 5 N HCL (hydrochloric acid); 2) $5 \mathrm{~N} \mathrm{NaOH}$ (sodium hydroxide); or 3) Clorox (6.25\% sodium hypochlorite). Using a light microscope, seedcoats after $\mathrm{NaOH}$ treatment were soft, easier to remove, and the seeds separated easily. The other two treatments hardened the seedcoat; thus, a 15-min soak in $5 \mathrm{~N} \mathrm{NaOH}$ was used in all germination trials.

\section{Seed germination trial}

Petroleum ether separation. A sample of $\approx 1500$ to 2500 unsorted $C$. e. $\times C . g$. hybrid seeds was separated by the petroleum ether method. Floaters and sinkers were soaked in $5 \mathrm{~N} \mathrm{NaOH}$ for 15 min followed by rinsing in tap water at room temperature for $48 \mathrm{~h}$ and then sown in a potting mixture of pine bark and peat $(7: 3)$ in clear plastic Magenta boxes (GA-7 vessels; Magenta Corporation, Chicago, IL). There were 25 seeds in each GA-7 vessel and eight replicate vessels for each treatment. Floaters and sinkers were germinated at 25 or $30^{\circ} \mathrm{C}$ in a growth chamber with a 12-h light/dark photoperiod. The number of germinated seeds was counted weekly for 8 weeks.

Seedcoat removal. Samples of $\approx 500$ unsorted hybrid seeds were soaked and rinsed as stated previously. Half of the seeds were placed directly on $0.8 \%$ agar (Fisher BioReagents, Fair Lawn, NJ) solidified water medium. The seedcoats of the other half of the seeds were carefully removed under a microscope and cultured on $0.8 \%$ agar solidified water medium. The medium was autoclaved at $1.2 \mathrm{~kg} \cdot \mathrm{cm}^{-2}$ for $30 \mathrm{~min}$. Germination took place in a growth chamber with a 12-h light/dark photoperiod at a temperature of $25^{\circ} \mathrm{C}$. There were 25 seeds per petri dish and eight replicates for the seedcoat-intact or removed treatments. The number of germinated seeds was counted weekly for 8 weeks.

\section{Experimental design and statistical analysis}

All experiments in this study were conducted using a completely randomized design. An analysis of variance of the germination percentage data was conducted using SAS (SAS Institute, Inc. 1999). Mean separation was by the least significant difference test at the $5 \%$ level.

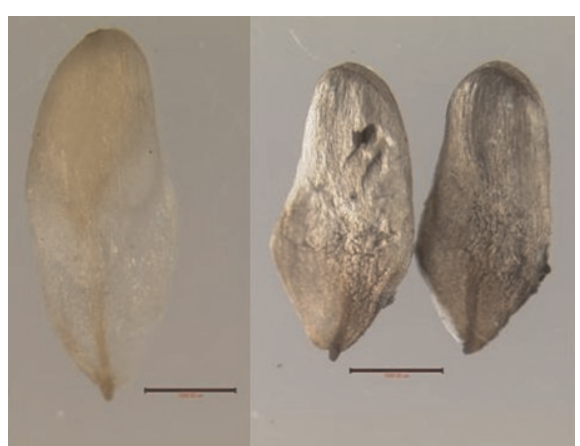

Fig. 1. Morphological categories of Casuarina hybrid (C. e. $\times$ C. g.) seeds. From left to right: filled, insect-damaged, and shrunken seeds. Bars $=1 \mathrm{~mm}$.

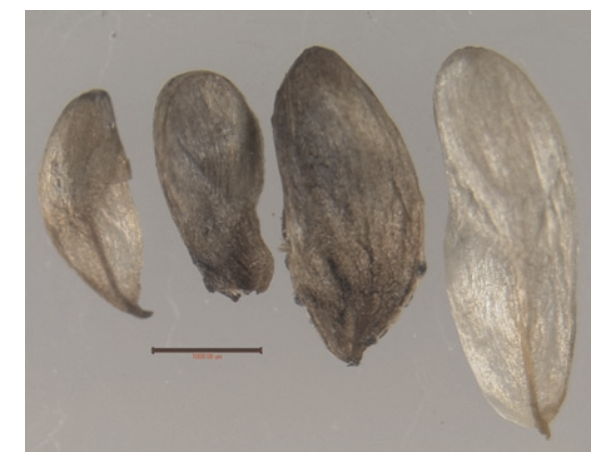

Fig. 2. Morphological categories of Casuarina cunninghamiana seeds. From left to right: empty, shrunken, insect-damaged, and filled seeds. Bar $=1 \mathrm{~mm}$.

\section{Results}

Seed morphological characteristics. The mean weight of 100 unsorted seeds of the $C$. e. $\times$ C. g. hybrid was $88 \mathrm{mg}$ and $67 \mathrm{mg}$ for unsorted seeds of $C$. $c$., which ranged from 62 to $76 \mathrm{mg}$ among the three source trees of C. $c$. (Table 1). Presumptive insect damage accounted for the largest percentage of seed types observed (Table 1). There were $47.5 \%$ to $93.0 \%$ insect-damaged seeds among floaters, but substantially fewer such seeds $(9.0 \%$ to $43.5 \%$ ) among sinkers. No empty seeds were observed among sinkers except for $C$. $c$. $\# 1$. The percentage of shrunken seeds was generally less than $20 \%$ among floaters and sinkers, although the sunken fraction of $C$. $c$. $\# 1$ and floating fraction of $C$. $c$. \#5 were considerably high. More than $50 \%$ of the sinkers were filled seeds, except C. c. \#1, which had a relatively small percentage of filled seeds. Less than $6 \%$ of the floating fraction was filled seeds, except for the Casuarina hybrid, which had 21\% filled seeds among floaters.

Seed germination performance after petroleum ether separation. Floaters germinated more slowly than sinkers. The earliest seed germination observed among sinkers was in the second week. The first sign of germination among floaters was in the third 
Table 1. Seed weight and seed types in floater (F) and sinker (S) fractions of Casuarina separated in petroleum ether.

\begin{tabular}{|c|c|c|c|c|c|c|c|}
\hline \multirow[b]{2}{*}{ Species } & \multirow{2}{*}{$\begin{array}{c}\mathrm{Wt} / 100 \\
\text { seeds }(\mathrm{mg})\end{array}$} & \multirow{2}{*}{$\begin{array}{c}\text { Seed } \\
\text { fraction }\end{array}$} & \multirow{2}{*}{$\begin{array}{c}\text { Total } \\
\text { no. }\end{array}$} & \multicolumn{4}{|c|}{ Percentage } \\
\hline & & & & Filled & Shrunken & Insect-damaged & Empty \\
\hline \multirow{2}{*}{ C.e. $\times$ C. g. hybrid } & 88 & $\mathrm{~F}$ & 134 & 20.9 & 8.2 & 71 & 0 \\
\hline & & $\mathrm{S}$ & 43 & 56.5 & 0 & 43.5 & 0 \\
\hline \multirow[t]{2}{*}{ C. cunninghamiana \#1 } & 62 & $\mathrm{~F}$ & 195 & 1.6 & 3.2 & 47.5 & 47.5 \\
\hline & & $\mathrm{S}$ & 110 & 5.5 & 39.1 & 40 & 15.5 \\
\hline \multirow[t]{2}{*}{ C. cunninghamiana \#5 } & 64 & $\mathrm{~F}$ & 100 & 5 & 41 & 49 & 5 \\
\hline & & $\mathrm{S}$ & 90 & 78 & 13 & 9 & 0 \\
\hline \multirow[t]{2}{*}{ C. cunninghamiana \#14 } & 76 & $\mathrm{~F}$ & 100 & 2 & 5 & 93 & 0 \\
\hline & & $\mathrm{S}$ & 100 & 74 & 17 & 9 & 0 \\
\hline
\end{tabular}

week with only $1 \%$ germination; sinkers had $10 \%$ germination during the same time period. Sinkers consistently had a higher seed germination percentage than floaters over a period of 8 weeks regardless of the temperature. The highest cumulative seed germination, $23.0 \%$, was obtained from sinkers at $30^{\circ} \mathrm{C}$ and $19.0 \%$ at $25{ }^{\circ} \mathrm{C}$; however, there was no significant difference among them nor was temperature a significant factor (Table 2).

Seed germination improvement with seedcoat removal. Seeds with seedcoats removed achieved their maximum percentage $(91 \%)$ within the first week as compared with only $1.2 \%$ germination among intact seed in the first week and $12.6 \%$ at the end of 8 weeks' culture (Table 3). When a seed germinated, the radicle emerged first followed by two cotyledons in 7 to $10 \mathrm{~d}$ (Fig. $3 \mathrm{~A})$. Seedlings grew to 5 to $10 \mathrm{~cm}$ in potting mixture in $\approx 2$ months (Fig. $3 B$ ).

\section{Discussion}

Unsorted seed of the four sources consisted of a large number of ungerminable seeds that were shrunken, insect-damaged, or empty. Those with presumptive insect damage appeared to be the major source of poor germination; shrunken seeds represented the second highest contributor to poor germination. Empty seeds were not a contributor except for C. c. \#1. These results for Florida

sources are consistent with previous studies of other Casuarina species, although the main causes of poor seed performance elsewhere varied depending on species, location, and cultural practices (Mahadevan et al., 1999; Sivakumar et al., 2007).

Casuarina seed germination percentages can vary from $14 \%$ to $50 \%$ depending on species (Boland et al., 1996; Jerlin and Srimathi, 1997). In our previous experiments, unsorted C.e. $\times$ C. g. hybrid seed germination percentages were only $\approx 1 \%$ (unpublished data). The current study demonstrated that sorting seeds on petroleum ether and planting only sinkers greatly improved Casuarina germination in comparison with unsorted seeds. The improved germination after petroleum ether flotation resulted from removing ungerminable seeds such as those in the empty category, which tended to collect in the floater fraction; no empty seeds were found in the sinker fraction; likewise, a much greater proportion of insect-damaged seeds were floaters rather than sinkers. Those seeds that had the highest germination percentage, filled seeds, generally were sinkers rather than floaters.

The percentage of filled hybrid seeds in the sinker fraction was $56.5 \%$. However, the cumulative maximum seed germination percentage of sunken seeds was $23.0 \%$. Thus, some normal-looking filled seeds did not germinate. One possible explanation is that
Table 2. Cumulative germination (\%) over 8 weeks in floater $(\mathrm{F})$ and sinker (S) fractions of Casuarina hybrid seeds in potting mixture at 25 and $30^{\circ} \mathrm{C} .^{\mathrm{z}}$

\begin{tabular}{lccccccccc}
\hline & Temperature & \multicolumn{7}{c}{ Percent germination at week } \\
\cline { 3 - 10 } Fraction & $\left({ }^{\circ} \mathrm{C}\right)$ & 1 & 2 & 3 & 4 & 5 & 6 & 7 & 8 \\
\hline $\mathrm{F}$ & 25 & 0.0 & 0.0 & 1.0 & 2.0 & 2.0 & 2.0 & 2.0 & $2.0 \mathrm{a}^{\mathrm{y}}$ \\
$\mathrm{F}$ & 30 & 0.0 & 0.0 & 0.0 & 0.0 & 1.0 & 1.0 & 1.0 & $1.0 \mathrm{a}$ \\
$\mathrm{S}$ & 25 & 0.0 & 1.0 & 6.0 & 17.0 & 22.0 & 23.0 & 23.0 & $23.0 \mathrm{~b}$ \\
$\mathrm{~S}$ & 30 & 0.0 & 0.0 & 10.0 & 16.0 & 19.0 & 19.0 & 19.0 & $19.0 \mathrm{~b}$ \\
\hline
\end{tabular}

${ }^{\mathrm{z}} \mathrm{A}$ total of 800 seeds were tested with eight replicates and 25 seeds per replicate for each treatment.

'Means followed by the same letter are not significantly different at $P \leq 0.05$. Analysis of variance results: floaters/sinkers effect: $P<0.001(F=117.36)$; temperature effect was not significant at $P<0.05$.

Table 3. Cumulative germination (\%) over 8 weeks of Casuarina hybrid seeds on $0.8 \%$ agar solidified medium with or without seedcoats at $25^{\circ} \mathrm{C} .{ }^{z}$

\begin{tabular}{lcccccccc}
\hline & \multicolumn{7}{c}{ Percent germination at week } \\
\cline { 2 - 9 } Seedcoat treatment & 1 & 2 & 3 & 4 & 5 & 6 & 7 & 8 \\
\hline Intact & 1.2 & 2.3 & 5.5 & 9.5 & 10.3 & 11 & 11.8 & $12.6 \mathrm{a}^{\mathrm{y}}$ \\
Removed & 91.0 & 91.0 & 91.0 & 91.0 & 91.0 & 91.0 & 91.0 & $91.0 \mathrm{~b}$ \\
\hline
\end{tabular}

${ }^{\mathrm{z}} \mathrm{A}$ total of 400 seeds were tested with eight replicates and 25 seeds per replicate for each treatment.

${ }^{\mathrm{y}}$ Means followed by the same letter are not significantly different at $P \leq 0.05$.
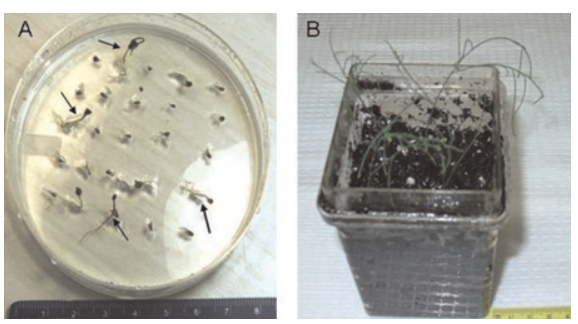

Fig. 3. Seed germination and seedling growth of a Casuarina hybrid (C. c. $\times$ C. g.). (A) Intact seeds were cultured on agar solidified medium and radicles emerged within 2 weeks (arrows); (B) seedlings grew in a potting mixture of pine bark and peat (7:3) after 2 months.

the seeds had low vigor and required more time to germinate. However, in the current study using filled seeds, the seedcoat was a major factor limiting germination rate and percentage. When the seedcoat was removed, a high germination percentage was achieved quickly.

Seed morphology affected the efficiency of the flotation technique. For the Casuarina hybrid, $20.9 \%$ of the floaters were filled seeds, but filled seeds were only $5 \%$ or less of the C. cunninghamiana floaters. Hybrid seeds were heavier with a larger surface area (wing) than seeds of $C$. cunninghamiana. Seeds from the C. cunninghamiana sources were variable in weight and size. Those differences may explain their behavior when separated with petroleum ether, which is not solely based on seed weight or size but specific gravity. A more appropriate flotation medium may separate germinable and ungerminable seeds with better efficiency (Demelash et al., 2003; Simak, 1973, 1984).

Most $C$. cunninghamiana seeds ( $78 \%$ and $74 \%$ for $\# 5$ and $\# 14$, respectively) collected from female trees in our study were normallooking and fully developed (filled); however, the TZ test showed that they were not viable. A study is underway to examine germination ability of seeds collected at different stages of cone maturity. It is important to determine the causes of low germination in C. c. sources because that is the only species permitted for windbreak use in Florida and only Florida sources are allowed.

\section{Conclusions}

Petroleum ether separation is a feasible means to improve seed germination performance in Casuarina species by separating germinable from ungerminable seeds. The technique was not perfect because some shrunken and insect-damaged seeds occurred in the sinker fraction and some filled seeds were floaters, but overall the technique provides a measurable advantage. Seedcoat removal might be another way to enhance hybrid seed germination because $91.0 \%$ germination is the highest in Casuarina ever reported. Presently, seed propagation of $C$. cunninghamiana is not permitted in Florida. Given our difficulties encountered so far with 
rooting cuttings, seed propagation may be important in the future, especially if a technique can be developed to identify plants by gender in the nursery.

\section{Literature Cited}

Barabin, A.I. 1983. Sorting seeds of pine and spruce by immersion in liquid. Lesnoi Zhurnal 6:120-121.

Boland, D.J., M.W. Moncur, and K. Pinyopusarerk 1996. Review of some floral and vegetative aspects to consider when domesticating Casuarina, p. 17-25. In: Pinyopusarerk, K., J.W. Turnbull, and S.J. Midgley (eds.). Recent Casuarina research and development. Proc. of the Third International Casuarina Workshop, Da Nang, Vietnam, 4-7 Mar. 1996.

Castle, W.S. 2008. Field guide to identify the common Casuarina (Australian pine) species in Florida. Univ. Fla. Coop. Extension Serv. Publ. HS 1140.

Castle, W.S., K.A. Langeland, and D.L. Rockwood. 2008. Casuarina cunninghamiana Miq. (River sheoak) in Florida and its potential as a windbreak plant for citrus groves. Univ. Fla. Coop. Ext. Serv. Publ. HS 1139.

Demelash, L., M. Tigabu, and P.C. Oden. 2003. Enhancing germinability of Schinus molle L. seed lot from Ethiopia with specific gravity and IDS technique. New For. 26:33-41.

El-Lakany, M.H., T.A. Omran, and M.S. Shehata. 1989. Variation in seed characteristics of Casuarina as affected by species, season of collection and positions on the tree crown. International Tree Crops Journal 5:237-245.

El-Lakany, M.H. and K.R. Shepherd. 1983. Variation in seed germinability, seedling growth, and biomass between provenances of Casuarina cunninghamiana Miq. and C. glauca Siev. Forest Mgmt. Ecol. 6:201-216.

El-Lakany, M.H., J.W. Trunbull, and J.L. Brewbaker (eds.). 1990. Advances in Casuarina research and utilization. Proc. 2nd Intl. Casuarina Wkshp, 15-20 January 1990, Desert Development Center, Cairo, Egypt.

Goh, C.J., P. Lakshmanan, C.L. Lee, C.S. Loh, and M. Tanaka. 1995. A simple and efficient method for clonal propagation of Casuarina sumatrana (de Vriese) L. Johnson. Plant Growth Regulat. 17:115-120.

Gottwald, T.R., J.H. Graham, and T.S. Schubert. 2002. Citrus canker: The pathogen and its impact. Online. Plant Health Prog. <http://www. plantmanagementnetwork.org/pub/php/review/ citruscanker/> doi: 10.1094/PHP-2002-0812-01RV.

Jerlin, R. and P. Srimathi. 1997. Grading and storage potential of Casuarina equisetifolia seeds. Ann. Forest 5:103-106.

Lundquist, R. and J.G. Torrey. 1984. The propagation of Casuarina species from rooted stem cuttings. Bot. Gaz. 145:378-384.

Mahadevan, N.P., V. Sivakumar, and B. Gurudevsingh. 1999. Relationship of cone and seed traits on progeny growth performance in Casuarina equisetifolia. Forst. Silvae. Genet. 48:273277.

Mani, G., A.S. Ponnuswamy, and K. Vanangamudi. 2002. Standardization of a seed processing technique to upgrade seed quality in Acacia leucophloea (Roxb.). Seed Res. 30:4346.

Martinez-Honduvilla, C.J. and A. Santos-Ruiz. 1978. Germination inhibitors in the pine seed coat. Planta 141:141-144.

McLemore, B.F. 1965. Pentane flotation for separating full and empty longleaf pine seeds. For. Sci. 11:242-243.

Midgley S.J., Turnbull, J.W., Johnston R.D. (eds.) 1983. Casuarina ecology, management and utilization. CSIRO, Melbourne, Australia.

Samasundaram, T.R. and S.S. Jagadees. 1977. Propagation of Casuarina equisetifolia Forst by planting shoots. Indian For. 103:735737.
SAS Institute, Inc. 1999. Version 8.02. SAS Institute, Cary, NC.

Simak, M. 1973. Separation of forest seed through flotation. Seed Problems IUFRO Symposium on Seed Processing, Bergen, Norway. Vol. 1, No. 16.

Simak, M. 1984. A method for the removal of filled-dead seeds from a sample of Pinus contorta. Seed Sci. Technol. 12:767-775.

Sivakumar, V., R. Anandalakshmi, R.R. Warrier, B.G. Singh, M. Tigabu, and P.C. Oden. 2007. Petroleum flotation technique upgrades the germinability of Casuarina equisetifolia seed lots. New For. 34:281-291.

Toole, E.H., S.B. Hendricks, H.A. Borthwick, and V.K. Toole. 1956. Physiology of seed germination. Annu. Rev. Plant Physiol. 7:299 324.

Turnbull, J.W. 1990. Taxonomy and genetic variation in Casuarinas, p. 1-11. In: El-Lakany, M.H., J.W. Turnbull, and J.L. Brewbaker (eds.). Advances in Casuarina research and utilization. Proc. 2nd Intl. Casuarina Wkshp., Desert Development Center, AUC, Cairo, Egypt.

Turnbull, J.W. and P.N. Martensz. 1982. Seed production, collection and germination in Casuarinaceae. Aust. For. Res. 12:281-294.

Turnbull, J.W. and P.N. Martensz. 1983. Seed production, collection and germination in Casuarina, p. 126-132. In: Midgley, S.J., J.W. Turnbull, and R.D. Johnston (eds.). Casuarina Ecology, Management and Utilization Melbourne, CSIRO.

Umarani, R. and K. Vanangamudi. 2002. The effect of specific gravity separation on germination and biochemical potential of Casuarina equisetifolia seeds. J. Trop. For. Sci. 14:207212.

Wilson, K.L. and L.A.S. Johnson. 1989. Casuarinaceae, p. 100-293. In: Flora of Australia, Hamamelidales to Casuarinales. Aust. Gov. Pub. Serv., Canberra, Australia. 